\title{
Design of Aviation High Impedance Permanent Magnet Synchronous Generator
}

\author{
Shitao Wu $\left(\mathbb{D},{ }^{1}\right.$ Qingguang Chen $\left(\mathbb{D},{ }^{1}\right.$ Qing Li, ${ }^{2}$ Xiangsheng Liu $\left(\mathbb{D},{ }^{3}\right.$ Hailin Zhang, ${ }^{4}$ and Li Lin ${ }^{5}$ \\ ${ }^{1}$ College of Mechanical and Electronic Engineering, Shandong University of Science and Technology, Qingdao, \\ Shandong Province 266590, China \\ ${ }^{2}$ Information Management Office of Shanghai Ocean University, Shanghai 201306, China \\ ${ }^{3}$ College of Electronmechanical Engineering, Sanda University, Shanghai 201209, China \\ ${ }^{4}$ College of Management, Sanda University, Shanghai 201209, China \\ ${ }^{5}$ Planning and Technology Office of Sanda University, Shanghai 201209, China
}

Correspondence should be addressed to Shitao Wu; wst@sdust.edu.cn

Received 19 October 2020; Revised 17 February 2021; Accepted 7 April 2021; Published 26 April 2021

Academic Editor: Marjan Uddin

Copyright (c) 2021 Shitao Wu et al. This is an open access article distributed under the Creative Commons Attribution License, which permits unrestricted use, distribution, and reproduction in any medium, provided the original work is properly cited.

Permanent magnet generator is one of the key components of a three-stage electrically excited brushless synchronous motor, with a main function to provide excitation power for the main exciter and driving power for the controller. In order to improve the reliability and safety of the operation of the three-stage electrically excited brushless synchronous motor, the permanent magnet generator is required to provide sufficient power under all operating conditions and to have low short-circuit current when its own short-circuit fault occurs, so that the generator will not be burnt out due to overheating. Thus, power characteristic and high impedance characteristic are the key goals of designing a permanent magnet generator. In this paper, the fractional slot concentrated winding was adopted to calculate and analyze the electromagnetic properties of permanent magnet generators with different rotor structures, and the optimal design was obtained. A prototype was manufactured to conduct related experiments on the electromagnetic properties. The results demonstrated that the experimental data are basically consistent with the simulation data, and the permanent magnet generator can meet the design requirements for power and high impedance characteristics, with a high power density.

\section{Introduction}

All-electric or more-electric system is an approach to achieve more fuel-efficient aircraft in the future which is easy to maintain [1, 2]. Characterized by large-capacity power supply system and extensive use of electric actuator to replace hydraulic and pneumatic actuators with high failure rates, all-electric or more-electric systems require the increase of capacity and reliability and the reduction in the volume and weight of the power system. The power capacity of Airbus A380 and Boeing 787 is $840 \mathrm{kVA}$ and $1450 \mathrm{kVA}$, respectively. With the development of the aviation power system, the main power supply used in modern aircraft includes the following types: $28 \mathrm{~V}$ low-voltage direct current (LVDC) power supply, $270 \mathrm{~V}$ high-voltage direct current
(HVDC) power supply, constant speed constant frequency (CSCF) AC power supply, variable speed constant frequency (VSCF) AC power supply, variable frequency variable speed (VSVF) AC power supply, and hybrid power source. Owing to the mature technology, high reliability, and good maintainability, the three-stage electrically excited brushless synchronous motor can not only be used in CSCF, VSCF, and VSVF power supply system but also can constitute LVDC and HVDC power supply system together with the output rectifier circuit, making it the preferred motor for the large-capacity power supply system of all-electric or moreelectric aircraft $[3,4]$.

The typical structure of a three-stage electrically excited brushless synchronous motor is shown in Figure 1. It consists of three coaxially connected motors: a revolving 


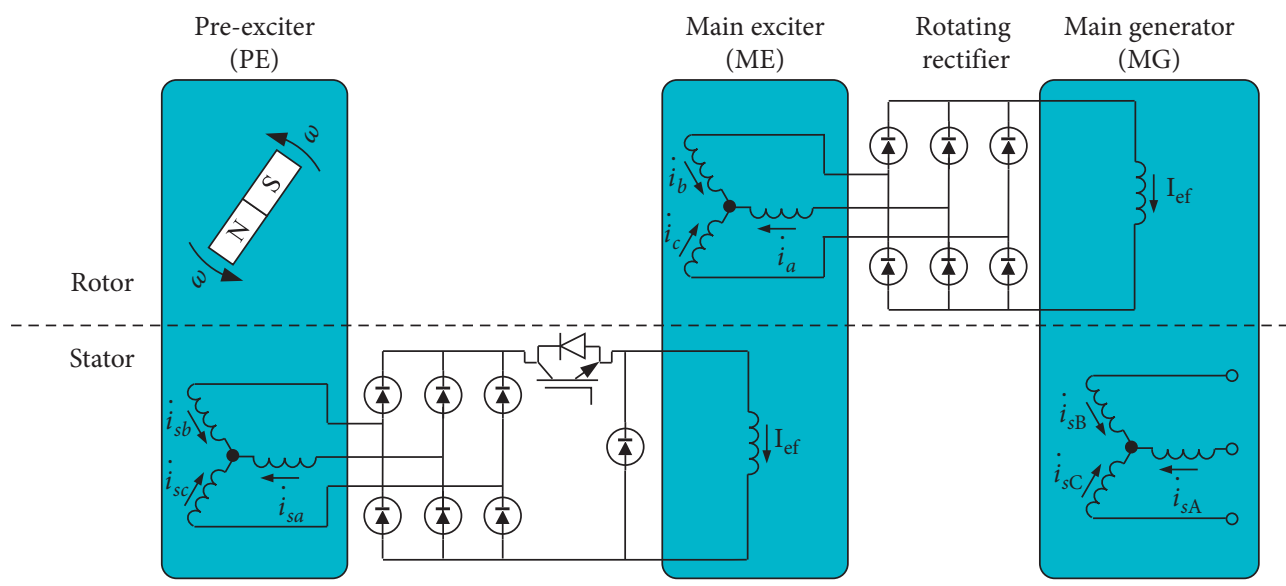

FIGURE 1: Structure of the three-stage electrically excited brushless synchronous motor.

pole electrically excited synchronous motor (also known as the main generator, MG), a revolving armature-type main exciter (ME), and a revolving pole permanent magnet generator (also known as pre-exciter, PE). In the power generation mode, the aeroengine drives the rotation of system rotor, and the stator winding of the permanent magnet generator cuts the synchronous rotating magnetic field produced by the permanent magnet to generate threephase alternating current, which provides DC exciting current for the excitation winding of $\mathrm{ME}$ and generates stator static magnetic field through the uncontrollable rectifier circuit and current regulating device. The armature winding of $\mathrm{ME}$ cuts this magnetic field under the rotation driven by the rotor and produces three-phase AC electric energy, which is supplied to the excitation winding of MG through an uncontrollable revolving rectifier to establish its synchronous rotating magnetic field that is cut by the stator winding of $\mathrm{MG}$ to generate electric energy for airborne equipment. This is how a three-stage electrically excited brushless synchronous motor works in the power generation mode.

Permanent magnet generator is one of the key components of a three-stage electrically excited brushless synchronous motor, and its electromagnetic properties are crucial to the reliability and safety of power system operation. In fact, the permanent magnet generator has two main functions: first, as shown in Figure 1, the three-phase output electric energy of the permanent magnet generator provides excitation power for ME through the uncontrollable rectifier circuit and the current regulating device, so that MG can achieve self-excited voltage build-up; second, the output electric energy of the permanent magnet generator provides the generator controller with the driving power needed for its own operation, and the $28 \mathrm{~V} \mathrm{DC}$ power supply inside the controller is only used as a reserve power supply. For permanent magnet generator, de-excitation at fault cannot be realized due to the existence of permanent magnet. Once short circuit occurs, large short-circuit current will be generated, usually several or even dozens of times the rated current. If it is not handled in time, the magnetic field of the generator will be severely distorted [5], and the temperature of the short-circuit winding will rise rapidly, hence damaging the winding insulation and burning out the generator. In addition, without electric energy output of the permanent magnet generator, the power system can only rely on $28 \mathrm{~V}$ reserve power supply to provide excitation power and driving power, which brings huge safety risks to the operation of the aircraft and threatens the lives of people on board. Therefore, studying and analyzing the reliability and safety of the operation of permanent magnet generator are of great theoretical and practical significance. Specifically, the power and high impedance characteristics are key indicators for the design of the permanent magnet generator.

\section{Operating Principle}

Permanent magnet generator used as PE has many advantages:

(1) Without the excitation winding and the collector ring and brush that are prone to failure, losses can be reduced, and efficiency and operating reliability can be improved.

(2) The use of rare Earth permanent magnet can increase the air gap flux density, thereby significantly reducing the volume of the generator and increasing the power density. The aviation power system has extremely strict requirement for the weight of the three-stage electrically excited brushless synchronous motor. The high power density of permanent magnet synchronous generator makes it suitable to be used as PE. At the same time, the permanent magnet generator does not need an external magnetic field, which is also the key to the realization of self-excited voltage build-up by the three-stage electrically excited brushless synchronous motor.

(3) Due to the small magnetic permeability, permanent magnet has much smaller direct-axis reactance of armature reaction than electrically excited synchronous generator. Thus, its inherent voltage regulation rate is also smaller than that of the electrically excited synchronous generator. 
Figure 2(a) shows the phasor diagram of the permanent magnet generator when it is connected to resistive and inductive load, and its voltage mode is

$$
E_{d}^{2}+E_{a q}^{2}=\left(U_{N} \cos \varphi+I_{N} R_{1}\right)^{2}+\left(U_{N} \sin \varphi+I_{N} X_{1}\right)^{2},
$$

where $E_{d}$ is the direct-axis air gap voltage, $E_{a q}$ is the quadrature-axis induced voltage, $U_{N}$ is the work output phase voltage of the generator, $I_{N}$ is the work output phase current of the generator, $R_{1}$ is the phase resistance, $X_{1}$ is the leakage reactance of phase winding, and $\varphi$ is the power factor angle.
The high impedance characteristic means that the permanent magnet generator has low short-circuit current, which is the key measure to improve the reliability and safety of the operation of permanent magnet generator. Its magnitude is measured by the multiple of short-circuit current $I_{k}^{*}$. Figure 2(b) shows the phasor diagram of the three-phase steady-state short-circuit operation of the permanent magnet generator, and $I_{k}$ is the output phase current under this condition. According to literature [5], the analytical expression of the multiple of short-circuit current is:

$$
\begin{aligned}
I_{k}^{*} & =\frac{4.44\left(\lambda_{n}-\lambda_{\sigma}\right) f N K_{d p} K_{\Phi} B_{r} A_{m} \times 10^{-4}}{4.44\left(1+\lambda_{\sigma}\right) \lambda_{n} f^{\prime} f N K_{d p} K_{\Phi} B_{r} A_{m} \times 10^{-4}+\left(1+\lambda_{n}\right) I_{N} \sqrt{R_{1}^{2}+X_{1}^{2}-X_{a q}^{2} \cos ^{2} \psi_{k}}} \\
\psi_{k} & =\arctan \frac{X_{a q}+X_{1}}{R_{1}}
\end{aligned}
$$

where $\lambda_{n}$ and $\lambda_{\sigma}$ are the synthetic permeance and leakage permeance of the external magnetic circuit of the permanent magnet generator, $f$ is the operating frequency, $N$ is the number of series turns of winding per phase, $K_{d p}$ is the fundamental wave winding coefficient, $K_{\Phi}$ is the air gap flux waveform factor, $\mathrm{Br}$ and $A_{m}$ are the residual magnetic induction of the permanent magnet and the cross-sectional area providing the magnetic flux per pole, $f$ is the armature magnetomotive force in each pair of pole magnetic circuit, $X_{a q}$ is the quadrature-axis reactance of armature reaction, and $\psi_{\mathrm{k}}$ is the internal power factor angle under short-circuit condition.

$X_{a q}+X_{1} \gg R_{1}, \psi_{K} \approx 90^{\circ}, I_{q} \approx 0$, and $I_{d} \approx I_{K}$, and it shows that the armature magnetic field almost plays a role of pure direct-axis demagnetization under short-circuit condition, that is, the magnetic field generated by the permanent magnet is almost offset by the demagnetized armature magnetic field when the generator is operating. At this time, the actual air-gap field is weak, and the generator works in a linear (unsaturated) state.

It can be known from formula (2) that there are various factors affecting the multiple of short-circuit current $I_{\mathrm{k}}{ }^{*}$, and the electromagnetic relationship is complicated, which is mainly manifested in the following aspects:

(1) The synthetic permeance $\lambda_{n}$ of the external magnetic circuit includes the permeance $\lambda_{\delta}$ of the main magnetic circuit and the permeance $\lambda_{\sigma}$ of the leakage magnetic circuit, and its magnitude depends on the physical dimension of each component of the generator. It has a significant impact on the parameters such as winding self-inductance, leakage inductance, and leakage coefficient.

(2) The inductance parameters of phase winding, including self-inductance, mutual inductance, and leakage inductance, are proportional to the square of the number of series turns of winding per phase $N$. The greater the inductance parameter of phase winding, the larger the impedance of the stator winding and the smaller the short circuit current.

(3) The length of the air gap has a significant impact on the saturation state of the generator operation, the air gap magnetic field synthesized by the magnetic field of permanent magnet, and the armature reaction magnetic field. The longer the air gap, the greater the reluctance and the smaller the synchronous reactance of the permanent magnet generator.

\section{Specific Design}

As aerogenerator is installed on aircraft, its dimension and weight are subject to extremely stringent specification. For permanent magnet generators, there are restrictions on the outer diameter of the stator, the axial length, and the inner diameter of the rotor. That is, the permanent magnet generator is required to meet the design requirements for both the power characteristic and high impedance characteristic in a limited space.

Fractional slot concentrated windings (FSCW) is a winding type with fractional number of slots per pole per phase and with a pitch of 1 , as shown in Figure 3. Such winding structure increases the short-chord effect and distribution effect of the winding and helps to increase the sinusoidal degree of the induced voltage waveform; the cogging torque frequency of the fractional slot winding is high, and the amplitude is small, which can reduce vibration and noise; the concentrated winding avoids the overlap of the phases at the end. Meanwhile, the electromagnetic coupling is small, which guarantees good electromagnetic isolation characteristic, and the small mutual inductance between phases decreases the probability of phase-to-phase 


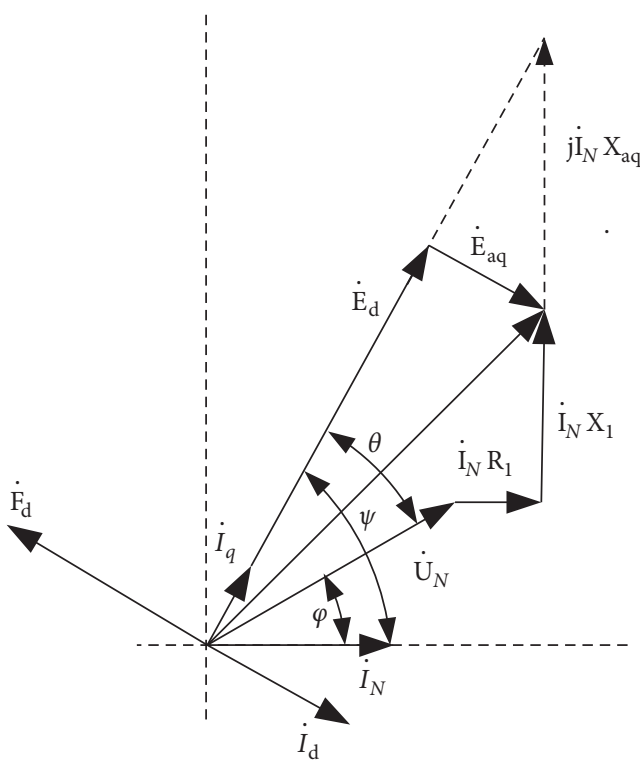

(a)

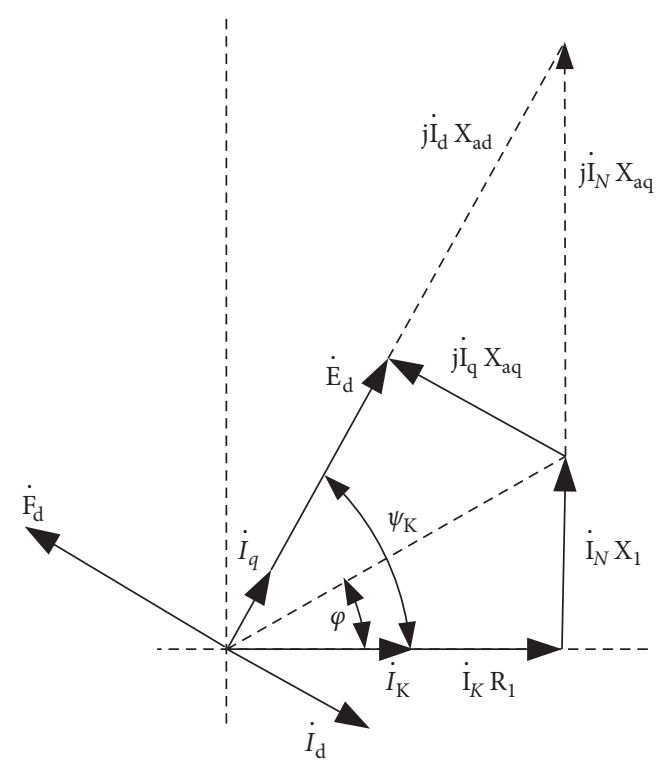

(b)

Figure 2: Phasor diagram of the stable operation of permanent magnet generator: (a) resistive and inductive load; (b) steady-state short circuit.

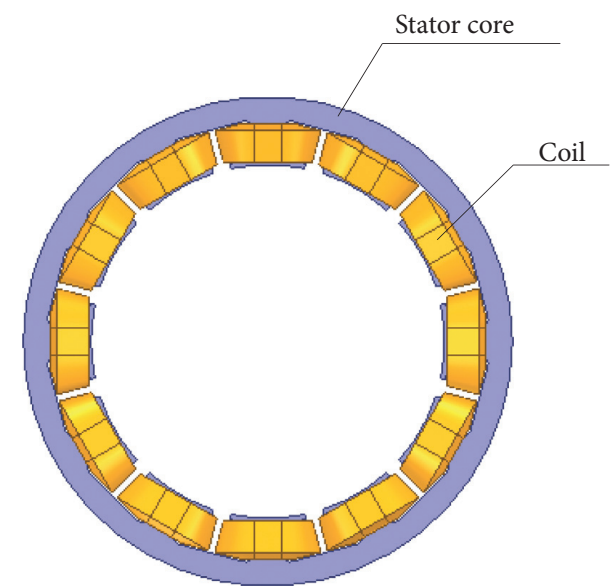

Figure 3: Fractional slot concentrated wingdings.

faults and enhances fault tolerance $[6,7]$; in addition, the large air gap inductance and slot opening magnetic leakage of FSCW increases self-inductance, which helps to suppress fault short-circuit current. Based on the technical characteristics and advantages of the abovementioned FSCW and considering the limited installation space of permanent magnet generator, the number of pole pairs of the permanent magnet generator designed in this paper was selected as $n_{p}=7$ and the number of stator slots was selected as $Z=12$. Then, the number of slots per pole per phase spp is

$$
s p p=\frac{Z}{2 \cdot n_{p} \cdot 3}=\frac{2}{7}
$$

Table 1 displays the phase diagram of the $14 \mathrm{p} 12 \mathrm{~s}$ slot vector. The numbers in the figure represent the corresponding coil numbers in the slot, and the "-" symbol
TABLE 1: Slot vector phase diagram.

\begin{tabular}{|c|c|c|c|c|c|c|c|c|c|c|c|c|}
\hline & 1 & 2 & 3 & 4 & 5 & 6 & 7 & 8 & 9 & 10 & 11 & 12 \\
\hline 1 & +1 & & & & & & & +2 & & & & \\
\hline 2 & & & +3 & & & & & & & +4 & & \\
\hline 3 & & & & & +5 & & & & & & & +6 \\
\hline 4 & & & & & & & +7 & & & & & \\
\hline 5 & & +8 & & & & & & & +9 & & & \\
\hline 6 & & & & +10 & & & & & & & +11 & \\
\hline 7 & & & & & & +12 & & & & & & \\
\hline 8 & & & & & & & -1 & & & & & \\
\hline 9 & & -2 & & & & & & & -3 & & & \\
\hline 10 & & & & -4 & & & & & & & -5 & \\
\hline 11 & & & & & & -6 & & & & & & \\
\hline 12 & -7 & & & & & & & -8 & & & & \\
\hline 13 & & & -9 & & & & & & & -10 & & \\
\hline 14 & & & & & -11 & & & & & & & -12 \\
\hline Phase & $\mathrm{A}$ & & B & & $\mathrm{C}$ & & & & & & & \\
\hline
\end{tabular}

denotes that the direction of the current in the coil is opposite to the direction of the coil current with the "+" symbol. The calculation results demonstrated that the pitchshortening factor of the fundamental wave winding is 0.966 , the distribution coefficient of fundamental wave winding is 0.966 , and then the winding coefficient of fundamental wave is 0.933 . Figure $4(\mathrm{a})$ shows the three-phase armature winding connection.

The number of turns of the coil is mainly determined by the output voltage class of the permanent magnet generator, and the output voltage is proportional to the number of turns of the coil. The selection of the wire diameter of winding mainly depends on the current density under rated condition. The greater the current density, the larger the winding loss, the greater the heat generated by the winding per unit time, and the larger the 


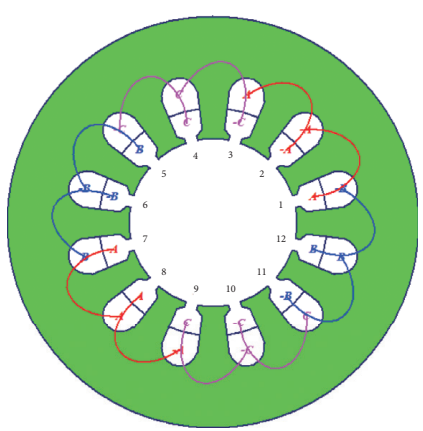

(a)

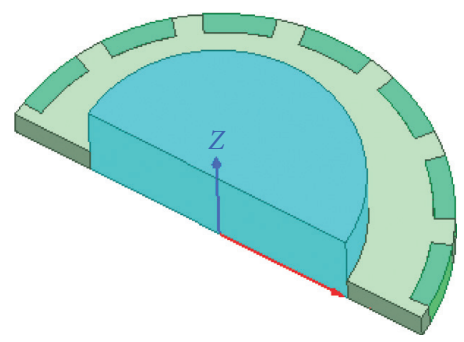

(d)

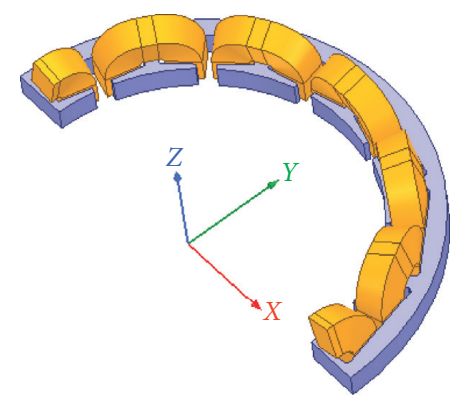

(b)

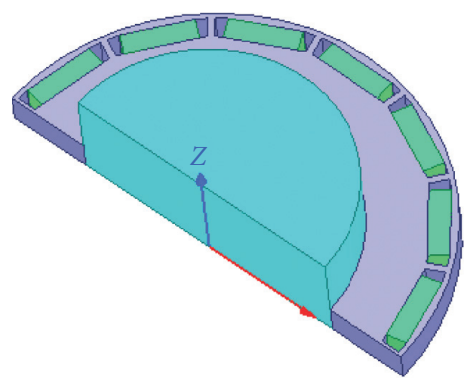

(e)

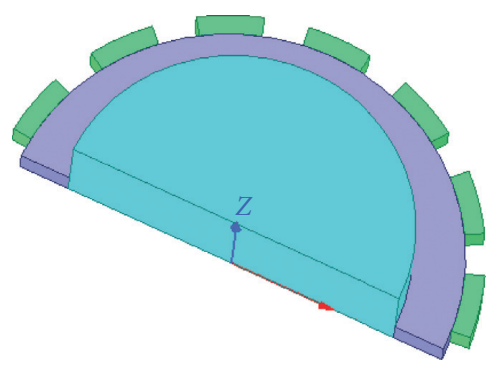

(c)

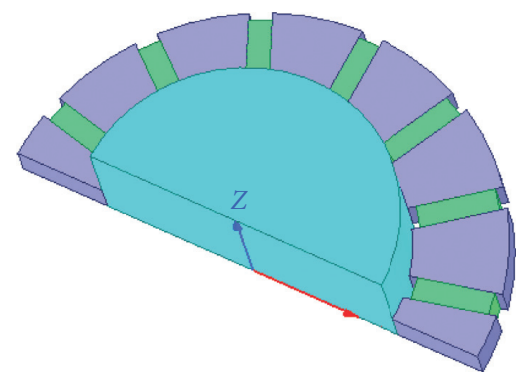

(f)

FIGURE 4: Distribution of winding of permanent magnet generator and different installation methods of permanent magnet. (a) Armature winding connection. (b) Stator component. (c) Surface magnet configuration: radially magnetized. (d) Inset magnet configuration: radially magnetized. (e) Buried magnet configuration: radially magnetized. (f) Buried magnet configuration: circumferentially magnetized.

impact on the insulation class of the winding and the magnetic properties of the permanent magnet. At the same time, considering that the permanent magnet generator should not be burnt when the winding is short circuited, the short-circuit current and short-circuit current density should be controlled within a safe range [8-10]. In this paper, the multiple of short-circuit current $I_{k}^{*}$ was required to be controlled within 2.1.

There are various installation methods of permanent magnet. The magnetomotive force and magnetic flux provided by the permanent magnet to the external magnetic circuit vary with different installation forms, which in turn has a significant influence on the electromagnetic properties of the generator. The common rotor structures of permanent magnet generators are shown in Figures 4(c)-4(f). In order to obtain the optimal design of the permanent magnet generator, the electromagnetic properties of four different rotor structures were analyzed in detail.

In order to avoid permanent demagnetization of the permanent magnet at high temperature and large current, the permanent magnet material is selected as $\mathrm{SmCo} 28 \mathrm{H}$, whose demagnetization curve is a straight line, as shown in Figure 5, and a loop line coincides with it. The Curie temperature of $\mathrm{SmCo} 28 \mathrm{H}$ is $820^{\circ} \mathrm{C}$, and the maximum operating temperature is $350^{\circ} \mathrm{C}$. Other parameters are shown in Table 2.

\section{Optimized Design}

Permanent magnet generators need to be designed as highimpedance motors to reduce short-circuit current and improve the reliability and safety of operation. Since the

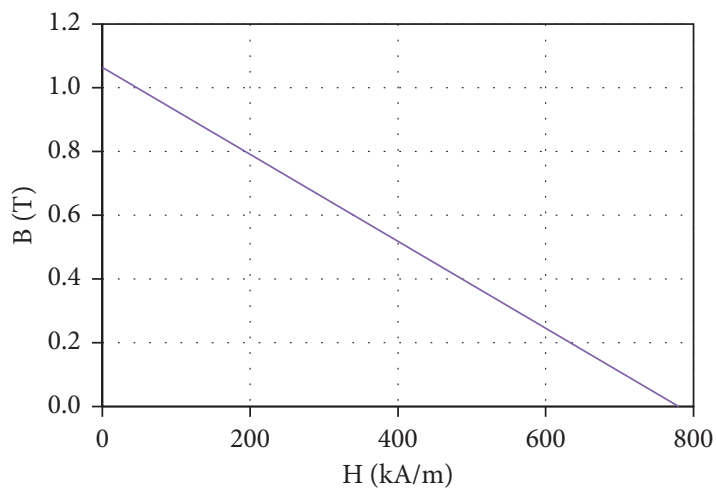

FIgure 5: Demagnetization curve of $\mathrm{SmCo} 28 \mathrm{H}$.

generator is a nonlinear and strong coupling multivariable system, it has a complicated electromagnetic relationship. Although the finite element calculation can obtain a more accurate numerical solution, it requires many calculation resources, long calculation time, and has low efficiency. Therefore, in this paper, the magnetic circuit method and the design of experiment (DOE) method were adopted to study the influence of the electromagnetic parameters of the permanent magnet generator on the short-circuit current and visualized related sensitivity information was provided, thereby saving time cost and enhancing design efficiency. This method is especially suitable for optimization design. According to (2), the influence of 10 design variables such as stator inner diameter (Di1) and stator tooth width (Toothwidth) on short-circuit current was explored. Table 3 
TABle 2: Performance parameter of SmCo28H.

\begin{tabular}{lccc}
\hline $\mathrm{Br}(\mathrm{T})$ & $\mathrm{Hcb}(\mathrm{kA} / \mathrm{m})$ & $\mathrm{Hcj}(\mathrm{kA} / \mathrm{m})$ & $(\mathrm{BH})_{\max }\left(\mathrm{kJ} / \mathrm{m}^{3}\right)$ \\
\hline 1.07 & 749 & 1990 & 215 \\
Curie temperature $\left({ }^{\circ} \mathrm{C}\right)$ & Operating temperature $\left({ }^{\circ} \mathrm{C}\right)$ & $\alpha(\mathrm{Br})\left(\% /{ }^{\circ}\right)$ & $\beta(\mathrm{Hcj})\left(\% /{ }^{\circ} \mathrm{C}\right)$ \\
820 & 350 & -0.03 & -0.2 \\
\hline
\end{tabular}

TABLE 3: Design variables.

\begin{tabular}{lcccc}
\hline Symbol & Name & Unit & Range & Physical meanings \\
\hline P2 & Di1 & $\mathrm{mm}$ & $68 \sim 77$ & Stator inner diameter \\
P3 & Len & $\mathrm{mm}$ & $8 \sim 16$ & Stator tooth width \\
P4 & Toothwidth & $\mathrm{mm}$ & $2 \sim 3.5$ & Stator slot opening height \\
P5 & hs0 & $\mathrm{mm}$ & $0.8 \sim 2.5$ & Stator slot height \\
P7 & hs2 & $\mathrm{mm}$ & $4 \sim 6.5$ & Stator slot opening width \\
P8 & bs0 & $\mathrm{mm}$ & $4 \sim 9$ & Number of turns of coil \\
P9 & $\mathrm{N}$ & - & $80 \sim 120$ & Permanent magnet pole-arc coefficient \\
P10 & Embrace & - & $0.5 \sim 0.9$ & Magnetizing direction length of permanent magnet \\
P11 & PM_H & $\mathrm{mm}$ & $2 \sim 5$ & Length of air gap \\
P12 & Gap & $\mathrm{mm}$ & $1.5 \sim 3$ &
\end{tabular}

exhibits the design variables and their physical meanings, in which the number of turns of coil $(N)$ is a discrete variable that can only be a positive integer.

Figure 6 shows a histogram of the sensitivity of the design variables to the short-circuit current when the number of coil turns $N=95$. The greater the sensitivity, the larger the influence of the design variable on the shortcircuit current. Positive sensitivity means that the shortcircuit current increases with the increasing design variable. Negative value means that the short-circuit current decreases with the increase of the design variable. It can be found from the analysis of Figure 6 that the dimension parameters of the permanent magnet (pole-arc coefficient and length of magnetizing direction), stator inner diameter, air gap length, and depth and width of stator slot opening have a great influence on the short-circuit current:

(1) The larger the embrace and PM_H, the greater the amount used by permanent magnet, the larger the magnetic field provided during operation, and the greater the corresponding short-circuit current. Therefore, under the premise of ensuring the operating point of the permanent magnet, the usage quantity of permanent magnet can be appropriately reduced to decrease the short-circuit current.

(2) The larger the Di1, the larger the air gap area per pole, which is equivalent to the increase of the synthetic permeance of the external magnetic circuit, so that the short-circuit current also rises accordingly.

(3) The larger the hs0 and bs0, the greater the leakage reactance of the stator slot body, which is beneficial to reducing the short-circuit current.

(4) The larger the gap, the greater the armature reaction reactance, which helps to improve the high impedance characteristic of the permanent magnet generator.

(5) The number of coil turns $N$ can only be a positive integer. The three-phase induced voltage of the permanent magnet generator is proportional to $N$, while

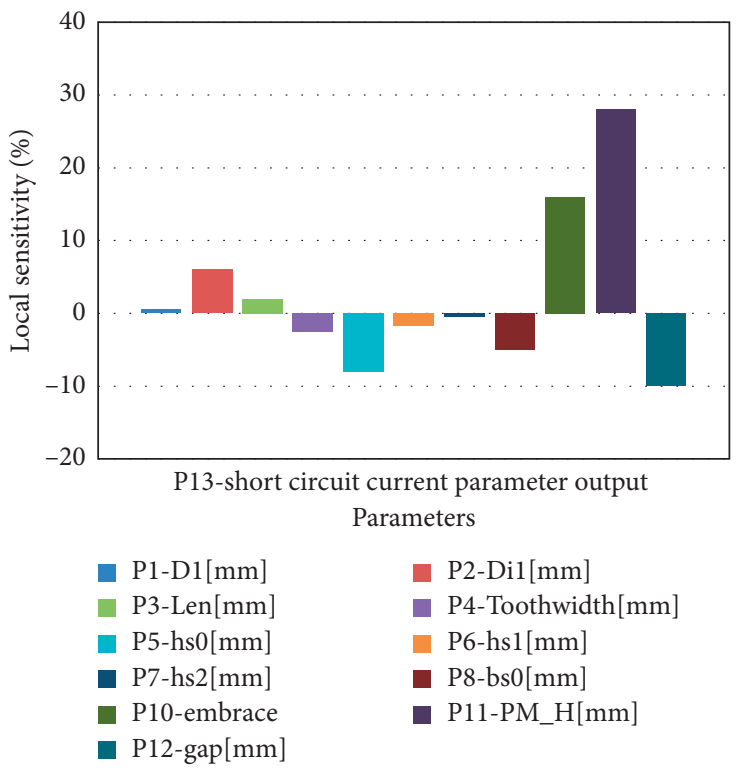

FIgURE 6: Analysis of sensitivity to short-circuit current of the permanent magnet generator.

the synchronous reactance is proportional to the square of $N$. Increasing $N$ is also one of the effective measures to improve the high impedance characteristic of the permanent magnet generator. The magnitude of $N$ also needs to meet the requirements for coil current density and stator slot fill factor.

\section{Simulation Calculation and Experimental Results}

Figure 1 shows that the permanent magnet generator is externally connected with three-phase uncontrolled rectified current circuit and a current regulating device and then provides adjustable exciting current to the ME to adapt to changes in the load and speed of the MG, so as to ensure 
stable output voltage. To facilitate analysis, the current regulating device was not considered in this paper. The external circuit of the permanent magnet generator is composed of a three-phase uncontrolled rectifier, resistive load, a voltmeter, and an ammeter, etc, as shown in Figure 7.

Permanent magnet generator has relatively large length radius ratio and serious magnetic flux leakage at the winding ends, which have a great impact on the electromagnetic properties. Thus, the three-dimensional finite element simulation models of permanent magnet generators with four different rotor structures were established in this paper, as shown in Figures 4(c)-4(f), where the parameters of stator components (stator structural parameters and winding parameters) are the same as the parameters of the rotor core. The permanent magnets are installed in different ways, but their volume is constrained to be the same. Accurate calculation and analysis of electromagnetic properties were conducted.

Table 4 presents the no-load leakage coefficients of the permanent magnet generators with four different rotor structures shown in Figures 4(c)-4(f). The magnetic permeability of the permanent magnet is close to that of air. Figure 4(c) shows the nonsalient pole structure, in which the quadrature-axis and direct-axis synchronous reactance is equal, the permanent magnet directly faces the air gap, and the magnetic field generated by the permanent magnet does not have magnetic flux leakage, with a leakage coefficient of 1 , and the magnetic field of permanent magnet can be fully utilized; Figures 4(d)-4(f) show the salient pole structures, where the quadrature-axis and direct-axis synchronous reactance is not equal. The magnetic field of the permanent magnet forms a magnetic flux leakage path through the ironcore material between the poles. The leakage coefficient is related to the installation method and structure parameters of permanent magnet. The larger the leakage coefficient, the smaller the utilization rate of the magnetic field of the permanent magnet, which will have a great impact on the electromagnetic properties. Figure 8 exhibits the A-phase induced voltage curves of the permanent magnet generators with four structures. The voltage effective value after stabilization is $110.78 \mathrm{~V}, 100.84 \mathrm{~V}, 75.32 \mathrm{~V}$, and $82.76 \mathrm{~V}$ respectively, and the value mainly depends on the utilization of the magnetic field of the permanent magnet.

Figures 9 and 10 present the external characteristics and power characteristic curves of permanent magnet generators with four structures. Given the same stator components (stator structure parameters and winding parameters), the voltage and power characteristics of the permanent magnet generator vary with the rotor structure and also depend on the utilization rate of the magnetic field of permanent magnet. The surface-mounted structure shown in Figure 4(c) has a leakage coefficient of 1 , and the magnetic field of permanent magnet can be fully utilized, exhibiting the highest output voltage and maximum output power.

In order to enhance the utilization rate of permanent magnet, increase the power density of permanent magnet generator and ensure the operating reliability, this paper finally selected the surface-mounted rotor structure shown in Figure 4(c) and fabricated a prototype. The three-phase

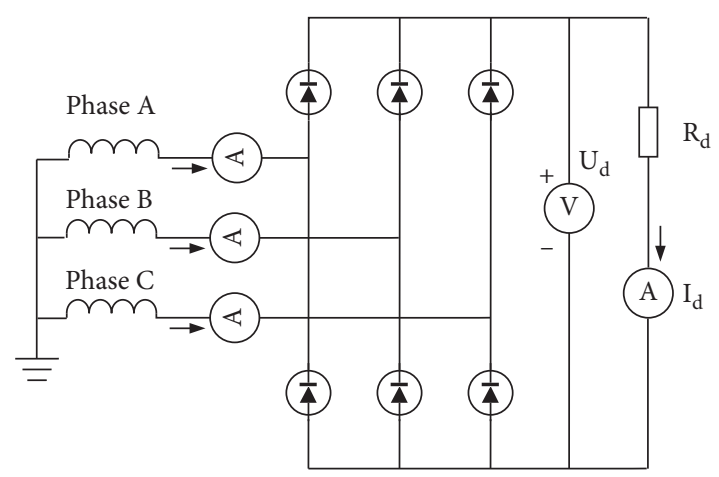

FiguRE 7: External circuit of the permanent magnet generator.

TABLE 4: Leakage coefficients.

\begin{tabular}{lcccc}
\hline Structure & Figure 4(c) & Figure 4(d) & Figure 4(e) & Figure 4(f) \\
\hline $\begin{array}{l}\text { Leakage } \\
\text { coefficient }\end{array}$ & 1 & 1.18 & 1.91 & 2.18 \\
\hline
\end{tabular}

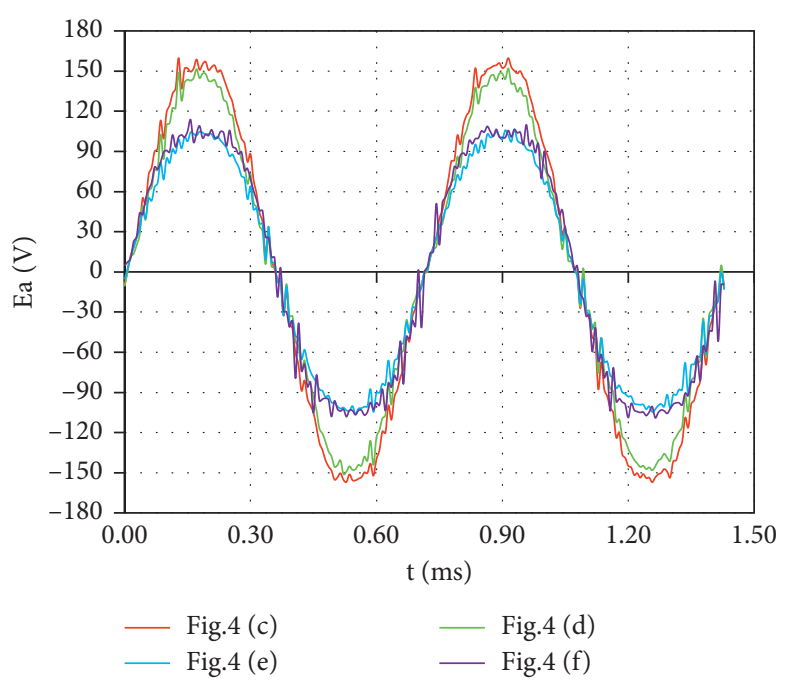

FIGURE 8: No-load characteristic curves of the permanent magnet generator.

uncontrolled rectified circuit was built based on the external circuit shown in Figure 6 to perform related experiments on electromagnetic properties.

Figures 11 and 12 present the simulation data and experimental data on the external characteristic and power characteristic of the surface-mounted permanent magnet generator. Thanks to the three-dimensional accurate modeling of the permanent magnet generator and the finite element calculation of the electromagnetic properties, the experimental data are basically consistent with the simulation data. The maximum required value of output power of the permanent magnet generator is $386 \mathrm{~W}$, and the maximum output power in simulation and experiment are $402 \mathrm{~W}$ and $425 \mathrm{~W}$, respectively, which meets the design 


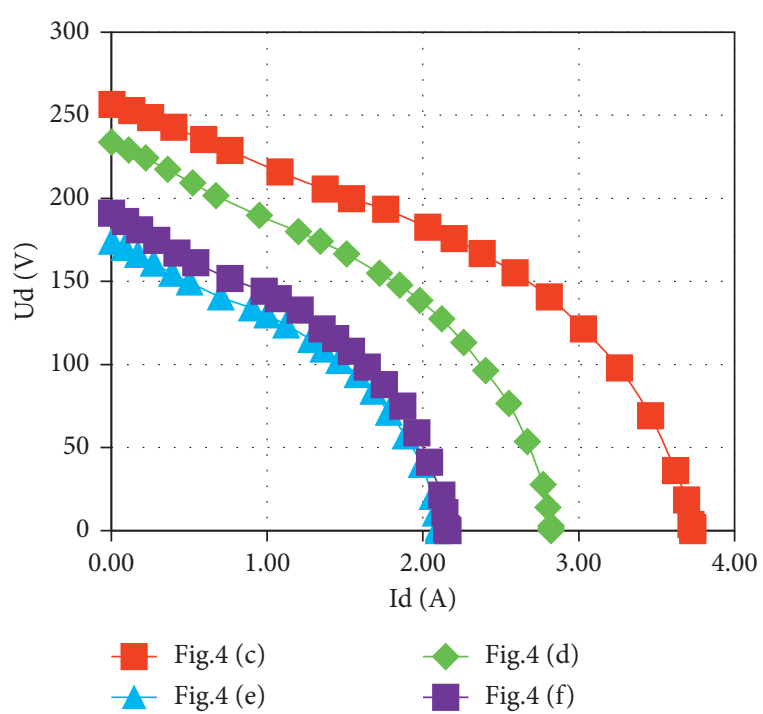

FIGURE 9: External characteristic curves of the permanent magnet generator.

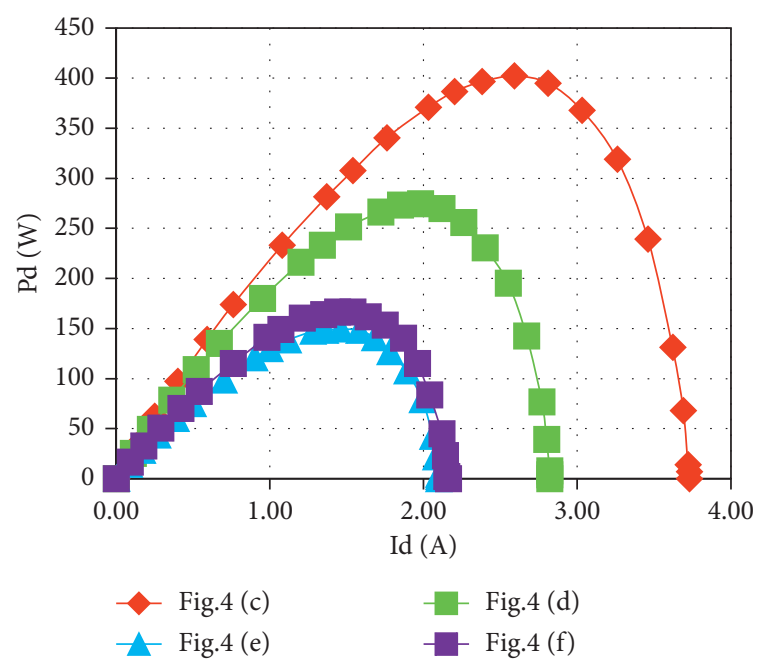

Figure 10: Power characteristic curves of the permanent magnet generator.

requirements and leaves sufficient margin to ensure that the permanent magnet generator has enough excitation power and driving power under all operating conditions.

High impedance characteristic (low short-circuit current characteristic) is one of the key design goals of aviation permanent magnet generator, and increasing the phase winding self-inductance is an effective approach to improve the high impedance characteristic. In this paper, the FSCW was used to increase the number of coil turns. Since the self-inductance of the phase winding is proportional to the square of the number of series turns of winding per phase, the impedance characteristic of the generator can be greatly improved using this method. Figure 13 displays the variation curve of A-phase self-inductance of the surfacemounted permanent magnet generator with load current. The change is relatively stable. The permanent magnet

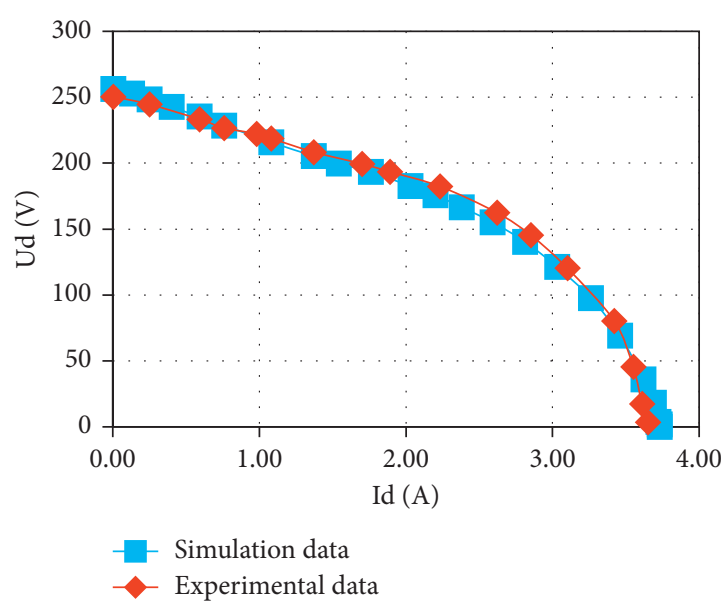

FIgURE 11: External characteristic curve.

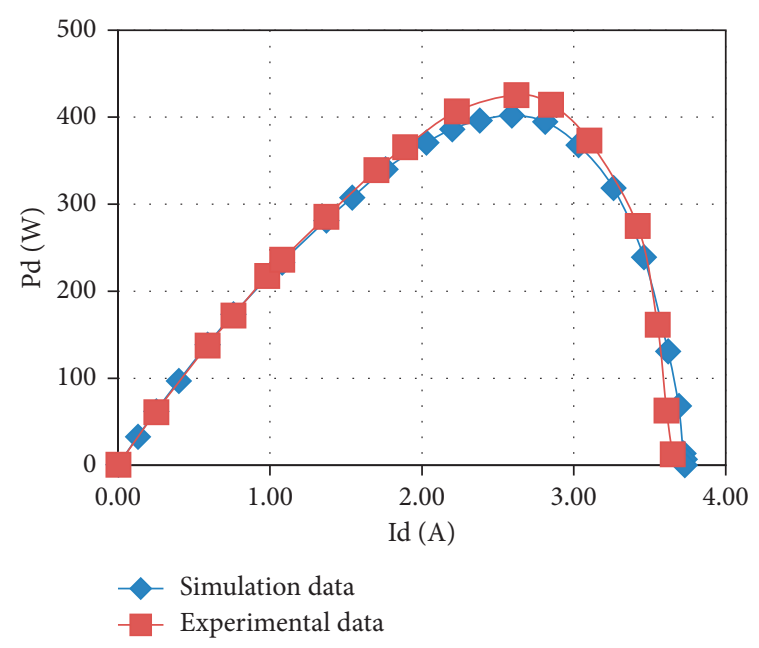

Figure 12: Power characteristic curve.

generator works in a linear (unsaturated) stage under each load. Figures 14 and 15 give the simulation data and experimental data of the three-phase current of the permanent magnet generator under the steady-state short-circuit condition. The effective value is $2.75 \mathrm{~A}$ and $2.7 \mathrm{~A}$, respectively. The simulation data are relatively consistent with the experimental data. Under the rated condition, the permanent magnet generator needs to output $340 \mathrm{~W}$ of power, the effective value of the three-phase output current is $1.33 \mathrm{~A}$, and the multiple of short-circuit current $I_{\mathrm{k}}{ }^{*}$ is about 2.03 .

Figure 16 is the cloud diagram of the simulation calculation of the magnetic density distribution of the permanent magnet under the short-circuit condition. The average magnetic density is between 0.7 and $0.8 \mathrm{~T}$. Figure 17 shows the three-phase no-load voltage curves of the prototype before and after the short-circuit test, which are basically consistent with each other, indicating that, under the short-circuit current action of the permanent magnet, no irreversible demagnetization occurs and the permanent magnet generator can still work normally. 


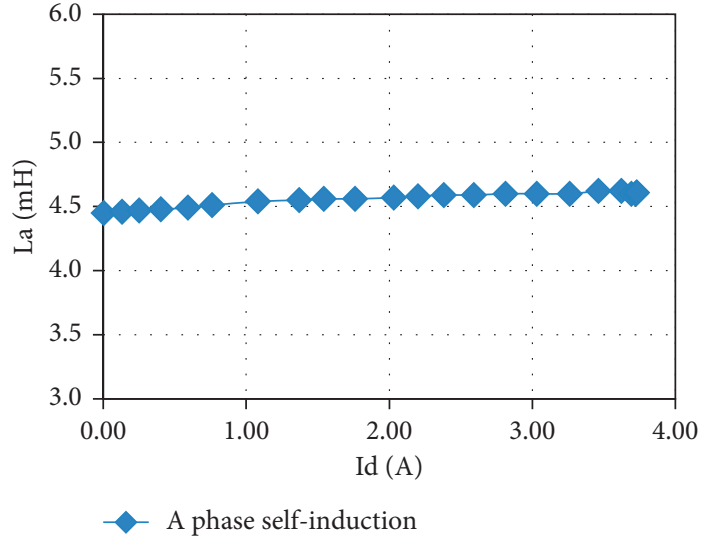

FIGURE 13: Variation curve of A-phase self-inductance with load current.

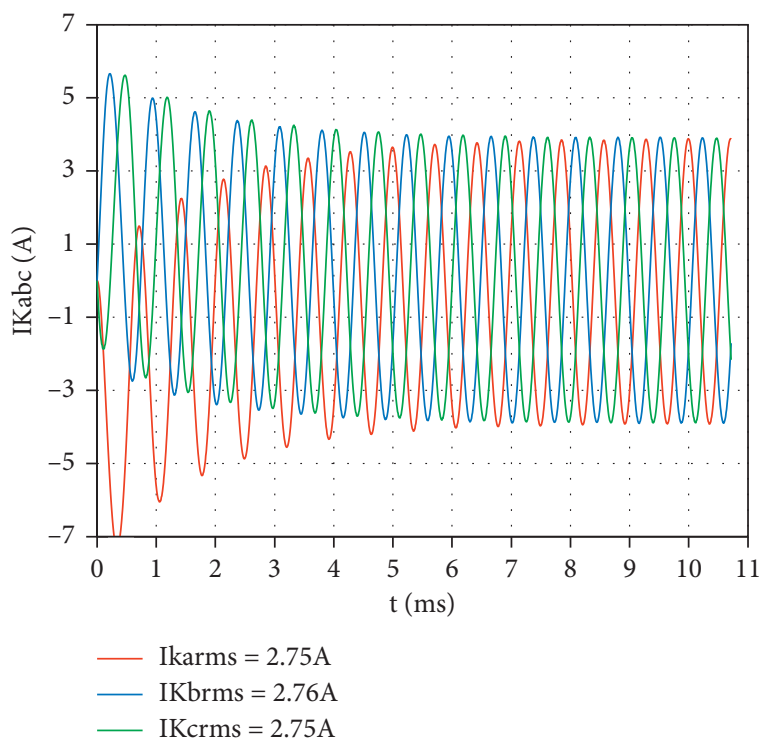

FIgURE 14: Three-phase short-circuit current of the permanent magnet generator: simulation data.

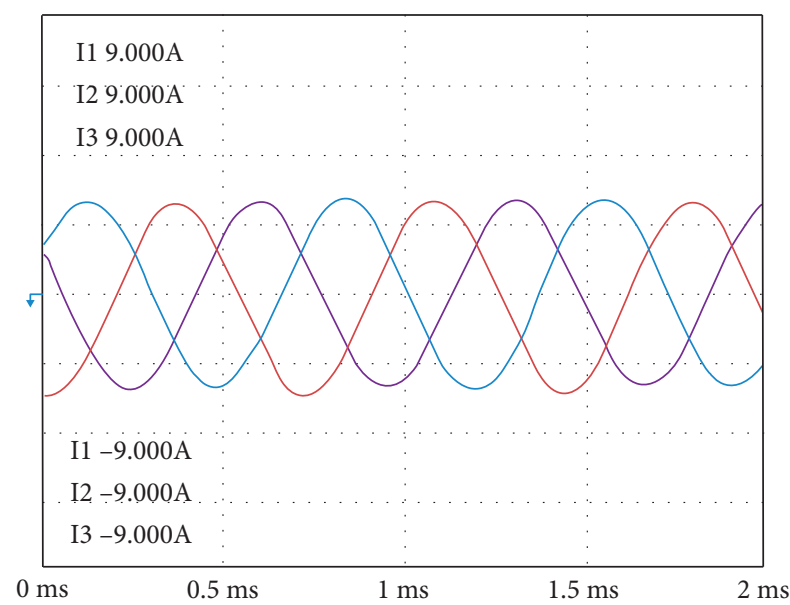

FIGURE 15: Three-phase short-circuit current of permanent magnet generator: experimental data.

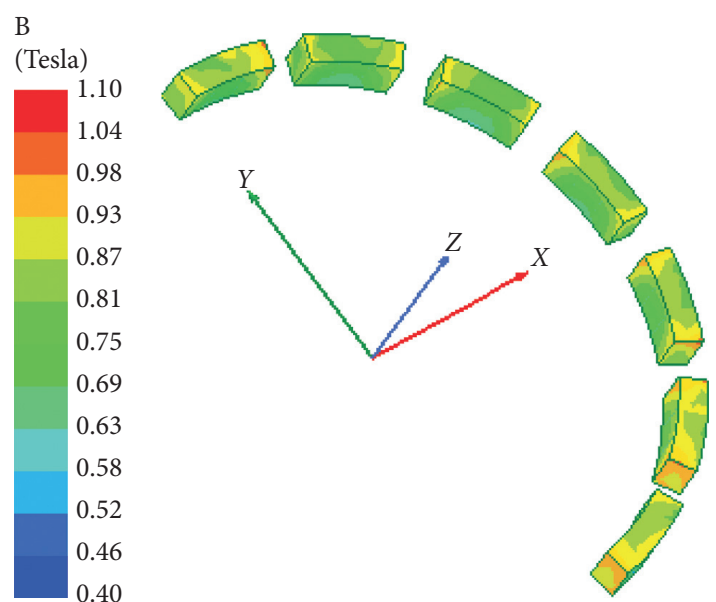

FIgURE 16: Cloud diagram of magnetic density distribution of permanent magnets under short-circuit condition.

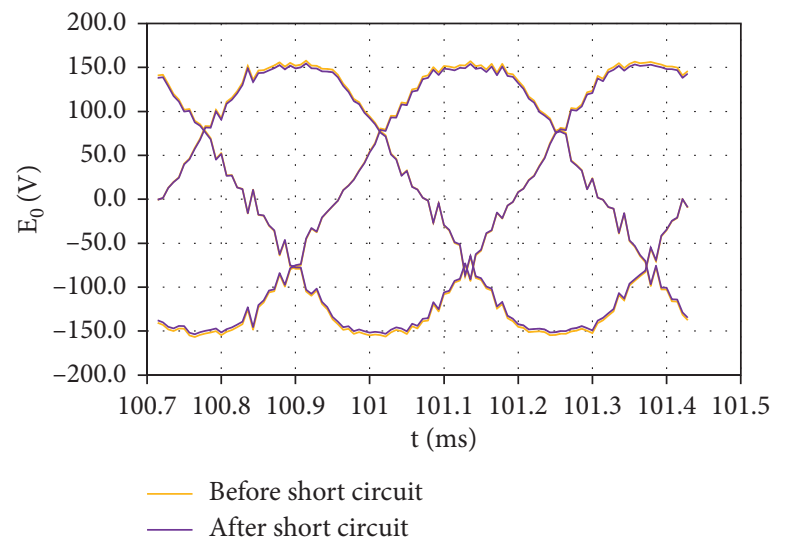

Figure 17: No-load characteristic curve before and after short circuit.

\section{Conclusion}

The permanent magnet generator is one of the key components of a three-stage electrically excited brushless synchronous motor, with main function to provide excitation power for the main exciter and driving power for the controller. In order to meet the design requirements for its power characteristic and high impedance characteristic, this paper adopted the fractional slot concentrated winding to increase the high impedance characteristic of the permanent magnet generator by enhancing the self-inductance of phase winding and optimizing the structural parameters, thereby reducing the short-circuit current. Then, the electromagnetic properties of four common rotor structures of permanent magnet were analyzed in detail. It was found that the permanent magnet generator with surface-mounted structure has no magnetic flux leakage, and the magnetic field of permanent magnet can be fully utilized, contributing to its greatest capability of power output and highest power density. Therefore, this paper finally selected the permanent 
magnet generator with surface-mounted structure and manufactured a prototype to conduct related experiments on electromagnetic properties. The simulation data are basically consistent with the experimental data. Its power characteristic meets the design requirements and leaves sufficient margin. The three-phase steady-state short-circuit current is small, about 2.03 times the rated operating current. The power characteristic and high impedance characteristic of the permanent magnet generator ensure reliability and safety of its operation under all operating conditions.

\section{Data Availability}

The raw/processed data required to reproduce these findings cannot be shared at this time as the data also forms part of an ongoing study.

\section{Conflicts of Interest}

The authors declare that they have no conflicts of interest.

\section{References}

[1] J. Chang, "Outlook of roles and necessities of power electronics for vf-power systems of future large aircraft," in Proceedings of the International Conference on Electrical Machines and Systems, pp. 1190-1195, Wuhan, China, October 2008.

[2] J. Chang and A. Wang, "New VF-power system architecture and evaluation for future aircraft," IEEE Transactions on Aerospace and Electronic Systems, vol. 42, no. 2, pp. 527-539, 2006.

[3] P. Ma, Starting Control Techniques of Aviation Brushless Synchronous Integated Starter/Generator System, Northwestem Polytechincal University, Xi'an, China, 2016.

[4] Z. Zhang, J. Huang, Y. Jiang, W. Geng, and Y. Xu, " Overview and analysis of PM starter/generator for aircraft electrical power system," CES TEMS, vol. 1, no. 2, pp. 117-131, 2017.

[5] R. Tang, Modern Permanent Magnet Machines Theory and Design, pp. 289-290, China Machine Press, Beijing, China, 2017.

[6] C. Gerada, K. Bradley, and M. Summer, "Winding turn-toturn faults in permanent magnet synchronous machine drives," in Proceedings of the Fourtieth IAS Annual Meeting. Conference Record of the 2005 Industry Applications Conference, pp. 1029-1036, Hong Kong, China, October 2005.

[7] L. EL-Refaie, J.-R. Riba Ruiz, and A. Garcia Espinosa, "Fractional-slot concentrated-windings synchronous permanent magnet machines: opportunities and challenges," IEEE Transactions on Industrial Electronics, vol. 57, no. 9, 2012.

[8] A. Romeral, O. A. Urresty, R. J. C. Riba et al., "Modeling of surface-mounted permanent magnet synchronous motors with stator winding inter-turn faults," IEEE Transactions on Industrial Electronics, vol. 58, no. 5, p. 1576, 2011.

[9] M. Fitouri, Y. Bensalem, and M. N. Abdelkrim, "Modeling and detection of the short-circuit fault in PMSM using finite element analysis," Ifac Papersonline, vol. 3, pp. 566-569, 2013.

[10] P. Arumugam, "Design optimization on conductor placement in the slot of permanent magnet machines to restrict turn-turn short-circuit fault current," IEEE Transactions on Magnetics, vol. 52, no. 5, Article ID 2516504, 2016. 